Cahiers $d u$ MONDE RUSSE

\section{Cahiers du monde russe}

Russie - Empire russe - Union soviétique et États indépendants

$59 / 4 \mid 2018$

Varia

\title{
Susanne Schattenberg, Leonid Breschnew. Staatsmann und Schauspieler im Schatten Stalins
}

Eine Biographie

Gábor T. Rittersporn

\section{(2) OpenEdition}

Journals

Édition électronique

URL : https://journals.openedition.org/monderusse/10777

DOI : 10.4000/monderusse. 10777

ISSN : $1777-5388$

Éditeur

Éditions de l'EHESS

Édition imprimée

Date de publication : 1 octobre 2018

Pagination : 670-673

ISBN : 978-2-7132-2747-9

ISSN : $1252-6576$

Référence électronique

Gábor T. Rittersporn, "Susanne Schattenberg, Leonid Breschnew. Staatsmann und Schauspieler im Schatten Stalins », Cahiers du monde russe [En ligne], 59/4 | 2018, mis en ligne le 01 octobre 2018, consulté le 08 janvier 2022. URL : http://journals.openedition.org/monderusse/10777 ; DOI : https:// doi.org/10.4000/monderusse. 10777 
Susanne SCHATTENBERG

\section{Leonid Breschnew}

\section{Staatsmann und Schauspieler im Schatten Stalins}

\section{Eine Biographie}

Cologne - Weimar - Vienne : Böhlau, 2017, 661 p.

Il arrive qu'un déclic change tout ou en tout cas beaucoup dans le regard qu'on porte sur un personnage. On découvre quelque chose qui place ce personnage sous une nouvelle lumière, dans une nouvelle perspective. Le connaisseur superficiel des âmes croit y trouver la clef universelle, l'explication de tout ce que notre homme représente. Le connaisseur prudent se contente de ranger la trouvaille parmi les autres clefs qui ouvrent telle ou telle autre porte ; il n'en abuse pas pour forcer celles qu'elle n'ouvre pas et ne désespère pas en constatant que la nouvelle clef ouvre davantage de pistes que la voie royale.

Susanne Schattenberg fait partie des connaisseurs prudents. Elle a la chance d'être tombée sur quelques clefs inattendues d'un personnage dont elle a traqué la trace pendant de longues années. Le personnage, Leonid Il'ič Brežnev, en a laissé d'innombrables dans une masse non moins innombrables de publications et dans les archives, mais c'est sa persona qui ressort de l'immense majorité des sources, le masque d'un Brežnev dont on a quelque raison de soupçonner qu'il a été créé par la propagande.

On pourrait espérer naïvement que les archives jadis secrètes et ultra-secrètes recèlent des documents susceptibles de révéler enfin la personne, mais nombre de collections restent fermées. Le chercheur doit faire le tour de l'univers ex-soviétique pour dépister dans une documentation éparpillée dans une multitude d'archives en Ukraine, dans l'Oural, en Moldavie et au Kazakhstan, les étapes que Brežnev dut gravir pour monter jusqu'à Moscou. Historienne chevronnée, Susanne Schattenberg a aussi exploré les archives des ministères des Affaires étrangères de la France et de l'Allemagne et les papiers de Willy Brandt à Berlin pour compléter tout ce qu'elle avait passé en revue dans sept archives de Moscou, la Rome où mènent presque tous les chemins de la recherche sur l'Union soviétique.

La persona est partout. Elle persiste même dans le carnet de bord singulier où le numéro un de l'Olympe soviétique notait occasionnellement et pêle-mêle des tâches à accomplir, des impressions, quelques événements et des occasions comme, par exemple, des anniversaires qu'il estimait nécessaires de souhaiter. Or Susanne Schattenberg s'intéresse à la personne. Elle veut éviter à tout prix d'écrire une biographie politique où, sous prétexte de raconter une vie, l'auteur suit l'histoire politique plus ou moins connue pour la lier tant bien que mal à ce qu'il croit comprendre du caractère, des idées, des projets et de l'autoperception de son protagoniste. Susanne Schattenberg réussit son pari. Elle découvre dans ses matériaux de 
petits indices qui permettent d'entrevoir quelque chose d'essentiel de l'individu et de dire si et à quel point il est commensurable à la persona. Il n'est pas simple de présenter en quelques phrases des recherches qui ont nécessité six cents pages pour être exposées. Il faut prendre le risque de simplifier à l'extrême.

Le Brežnev qui est présent dans les esprits est le vieillard quelque peu comique qu'on voyait sur les écrans vers la fin des années 1970. Un fossile aux gestes incertains qui se déplaçait maladroitement et qui articulait mal ses mots au point d'être peu compréhensible pendant les rapports fleuve qu'il présentait aux assemblées de ses fidèles. L'image de lui retenant à grand effort son chapeau que le vent allait enlever à l'aéroport de Cologne en novembre 1981, un an avant sa mort, avait quelque chose d'emblématique de cette période de sa vie.

On se souvient à peine du personnage galant aux mouvements dynamiques qu'on voyait une vingtaines d'années plus tôt quand, dans le rôle du chef de l'État fictif de l'URSS, il inaugurait allègrement des roses, s'entretenait avec ses homologues étrangers et plaisantait lors des nombreuses remises de décorations. Les heureux élus riaient-ils par politesse ou les blagues étaient-elles vraiment bonnes ? On aurait aimé le savoir. Il arrivait parfois que l'on pût en capter quelques bribes quand il descendait du sommet de l'État-Parti pour visiter des villes, des usines, des unités de l'armée, des écoles primaires et d'autres institutions et, très rarement, des établissement d'enseignement supérieur et des kolkhozes. Souvent, elles ne volaient pas haut. Mais le fait même qu'il les raconte tranchait notablement avec les manières de son prédecesseur, Nikita Sergeevič Hruščev, qui avait une forte tendance à parler en autorité suprême, à monter sur ses grands chevaux et à ne pas faire grand cas du respect de ses interlocuteurs. Brežnev était plutôt modeste, poli et attentif à l'amour-propre de son monde, même quand il donnait des leçons.

Susanne Schattenberg a compris que ce comportement attentif fournissait l'une des clefs d'accès au personnage. Son héros a tiré des leçons précieuses de son apprentissage à l'ombre de toutes sortes de petits Hruščev ainsi qu'à l'ombre de leur grand maître, Stalin. Sa lecture des matériaux révèle qu'à la différence des chefs que Brežnev a subis ou côtoyés au cours de son ascension, le futur secrétaire général prenait au sérieux le discours officiel sur le soin dont il convenait d'entourer le peuple et les cadres. Il évitait de se poser en dirigeant puissant et faisait tout pour manifester ses égards à ses subordonnnés et au reste de la société. Le compromis que l'État-Parti a conclu avec une population qui ne se pliait pas aisément à la discipline bolchevique, l'émergence d'une version pauvre de la société de consommation et l'attention qu'on a commencé à porter aux plaintes que les travailleurs adressaient aux institutions (dont les objets feront partie des accusations que la perestroïka lancera aux apparatchiki) témoignaient de la sincérité de l'intention de Brežnev d'apaiser les tensions qu'il connaissait bien des années de son apprentissage.

De même, la détermination de L.I. Brežnev à garantir la stabilité au sein des appareils et à en finir avec la longue tradition de faire travailler les cadres sous la menace de devenir les boucs émissaires des échecs du régime et d'être destitués et punis montrent qu'il a pris au sérieux les enseignements de ses années de formation. Il a évité les règlements de comptes, même avec ses rivaux de longue date, 
et a su attendre le moment où il était justifié de les envoyer à la retraite. Pendant une trentaine d'années, les cadres eurent sans doute quelque raison de trembler en découvrant que c'était le chef de tous les chefs qui était au bout du fil. Brežnev avait l'habitude de les appeler pour leur demander s'ils avaient besoin d'aide dans leur travail, leur souhaiter un bon anniversaire ou s'assurer qu'ils étaient rétablis d'une maladie. Certes, il attendait des résultats, mais il savait d'expérience que la pression permanente ne servait à rien.

Susanne Schattenberg consacre un chapitre fascinant à l'exercice par Brežnev de sa prérogative régalienne à conduire la politique étrangère. Elle documente l'importance que le maître prudent du Kremlin attribuait aux rapports personnels avec ses interlocuteurs illustres qui dirigeaient de petites ou de grandes puissances. Elle réussit à dégager de ses sources les mille façons dont il tentait de nouer et de maintenir des relations de confiance avec des partenaires qui n'étaient pas toujours d'un commerce facile. Il veillait à ce que les leaders des pays satellites bénéficient $d u$ même respect que ses cadres à tous les niveaux de l'appareil soviétique. L'issue des tentatives de réforme de la direction tchécoslovaque en 1968 montre que ses efforts n'étaient pas toujours couronnés de succès, mais les rapports qu'il est parvenu à établir avec les leaders occidentaux étaient prometteurs.

Il fallait avoir la persévérance de Susanne Schattenberg pour dépister les sources d'où il ressort que les relations cordiales que Brežnev a nouées avec Richard Nixon, Georges Pompidou et Willy Brandt jouèrent un rôle éminent dans la détente entre les grandes puissances, même en pleine de guerre du Vietnam. Ces relations permettaient de court-circuiter les canaux diplomatiques et d'échapper à la vigilance des états-majors. Elles étaient d'autant plus nécessaires qu'en théorie le secrétaire général n'avait rien d'un interlocuteur valable pour les politiciens occidentaux car, officiellement, il ne fut pas chef de l'État avant 1977. La communication plus ou moins informelle au sommet fonctionna de mieux en mieux jusqu'en 1974, annus horribilis pour les efforts diplomatiques de Brežnev. La mort de Pompidou et la démission de Nixon et de Brandt inaugurèrent une période d'une dizaine d'années pendant laquelle les rapports personnels entre les dirigeants soviétiques et leurs homologues occidentaux furent pour le moins distants.

Susanne Schattenberg a également trouvé la source de l'habileté de Brežnev à se présenter comme le dirigeant prévenant d'un État autoritaire et le représentant avenant d'un régime défendant bec et ongles son statut de grande puissance et ce qu'il prenait pour ses périmètres de sécurité. Dans sa prime jeunesse, le secrétaire général avait été un acteur amateur passionné. Moyennant l'analyse subtile de quelques photographies, Susanne Schattenberg dévoile le talent du jeune Brežnev à se mettre en scène comme un homme des temps nouveaux et à se montrer élégant, chose qui n'allait pas de soi à un moment où l'on attendait plutôt d'un individu qui voulait monter en grade qu'il fît preuve des manières dures du prolétaire combatif. Il a misé sur le bon cheval en anticipant une époque où l'habitus qu'on jugeait civilisé, la kul'turnost', serait à l'honneur au sein de l'appareil. La rumeur veut que c'est son élégance d'apparatchik provincial qui ait attiré l'attention de Stalin en 1952 quand il s'est agi de choisir les membres du présidium du comité central. 
Quoiqu'il en soit, nous savons pour sûr, grâce à cette excellente biographie, que notre apparatchik voulait que ses collaborateurs suivent son exemple. Nous apprenons également qu'à la demande de Paris Match, il enverra une photo où il croira imiter Alain Delon.

Manifestement, la propagande a saisi une persona que Brežnev lui-même a créée. L'une des clefs du personnage est donc sa capacité à paraître. Susanne Schattenberg ne se perd pas en conjectures pour aller plus loin et tenter de révéler un supposément authentique Brežnev qui se cacherait derrière son talent de comédien. Elle résiste à la tentation de voir le vrai Brežnev dans le vieillard vaniteux qui adore le culte qu'on essaye de construire autour de sa personne avec des résultats qui se révéleront douteux peu après sa mort. La dépendance médicamenteuse qui caractérise ses dernières années ou sa mémoire défaillante qui contraint ses collaborateurs à lui glisser des antisèches, même pendant des négociations internationales, sont des rôles ingrats que notre acteur n'aurait certainement pas voulu jouer. Son véritable emploi était celui du Brežnev méconnu des années de sa formation et celui du Brežnev oublié de l'époque de sa splendeur que Susanne Schattenberg décrit admirablement.

Gábor T. Rittersporn

CERCEC, CNRS, EHESS, PSL 